\title{
Voiding and Sexual Dysfunction in a Young Patient After Dengue Fever
}

\author{
Ana B. Bogdan ${ }^{\text {a, c }}$, Rodrigo G. Silva ${ }^{\mathrm{b}}$, Joao P. Fantin ${ }^{\mathrm{a}}$, Gabriel G. Santos ${ }^{\mathrm{a}}$, Luis C. Spessoto ${ }^{\mathrm{a}}$, \\ Fernando N. Facio, Jr. ${ }^{\mathrm{a}}$
}

\begin{abstract}
Dengue fever is the most prevalent viral disease caused by arthropods in the world. Post-dengue neurological complications have been reported in less than $1 \%$ of cases. Urinary and sexual dysfunctions after complications of dengue infection are rare. We report a case of a young patient who presented with transverse myelitis after dengue infection and evolved with voiding and sexual dysfunction. Transverse myelitis after dengue is a rare complication, especially in young patients with no other risk factors who evolve with voiding and sexual dysfunction.
\end{abstract}

Keywords: Micturition disorders; Erectile dysfunction; Dengue fever

\section{Introduction}

Dengue fever is the most prevalent viral disease caused by arthropods in the world [1]. Neurological complications after dengue, including encephalitis, encephalopathy metabolic disorder, and neuromuscular and neuro-ophthalmological complications, have been reported in less than $1 \%$ of cases [2].

Urinary and sexual dysfunctions after neurological injuries are relatively common, but these disorders resulting from dengue infection are rare. In this case report, we present a case of a young patient with voiding and sexual dysfunction after dengue.

\footnotetext{
Manuscript accepted for publication November 10, 2016

aDepartment of Urology, Hospital de Base of the Medicine School in Sao Jose do Rio Preto, Sao Jose do Rio Preto, Sao Paulo, Brazil

${ }^{b}$ General Surgery Department, Hospital de Base of the Medicine School in Sao Jose do Rio Preto, Sao Jose do Rio Preto, Sao Paulo, Brazil

${ }^{\mathrm{c}}$ Corresponding Author: Ana B. Bogdan, Departamento de Urologia, Hospital de Base da Faculdade de Medicina Sao Jose do Rio Preto, Av. Brig. Faria Lima 5416, Sao Jose do Rio Preto, Sao Paulo, CEP 15090-000, Brazil. Email: anapaulabogdan@terra.com.br
}

doi: https://doi.org/10.14740/jem380e

\section{Case Report}

We report the case of a 21-year-old male patient with dengue confirmed by an investigation of anti-dengue IgM antibodies (rapid test Alere SA) associated with clinical and epidemiological signs and symptoms according to the criteria of the Brazilian Ministry of Health [3]. The acute infectious symptoms were resolved and laboratory tests normalized within 2 days. However, the patient evolved with urinary retention, paresthesia and paresis of the lower limbs. The examination showed normal mental state, coordination, cranial nerves and deep reflexes, but bilateral absence of cutaneous abdominal sensitivity, bilateral positive Babinski reflexes, clonus of both lower limbs without dysarthria, no deviation of the eyes and no involuntary movements.

An examination of the cerebrospinal fluid showed lymphocytic pleocytosis with no other changes except positivity for anti-dengue IgG antibodies. No other infectious and autoimmune diseases were detected. Magnetic resonance imaging (MRI) of the skull, neck and chest showed hyperintensity of the T1-T10 segment in the thoracic spinal cord compatible with transverse myelitis (Fig. 1).

The patient had marked improvement in the lower limb deficiency after 5 days of pulse therapy with methylprednisolone, but the voiding dysfunction persisted with reduced flows and high post-void residual urine volume. On presenting spontaneous urination, the patient did not accept clean intermittent bladder catheterization. After 9 months, he had improved urinary flow, but remained with post-void residual urine volume, increased frequency and urgency, difficulty to pass urine and to maintain erection.

Hormone levels were within the normal range (Table 1). A urodynamic examination showed reduced sensitivity of the urinary bladder, neurogenic detrusor overactivity with urgency but without loss, and voiding with low flow rates at high pressure. The Schafer nomogram identified grade II obstruction and a normal detrusor function (Fig. 2).

Medical treatment associated $6 \mathrm{mg}$ solifenacin and $0.4 \mathrm{mg}$ tamsulosin per day to inhibit involuntary detrusor contractions and reduce urethral resistance by relaxing the urethra with consequent improvement in urinary flow and a reduction in residual urine. Due to complaints of erectile dysfunction, the patient was referred for a psychotherapeutic evaluation as well as treatment with phosphodiesterase type 5 (PDE-5) inhibitors. 


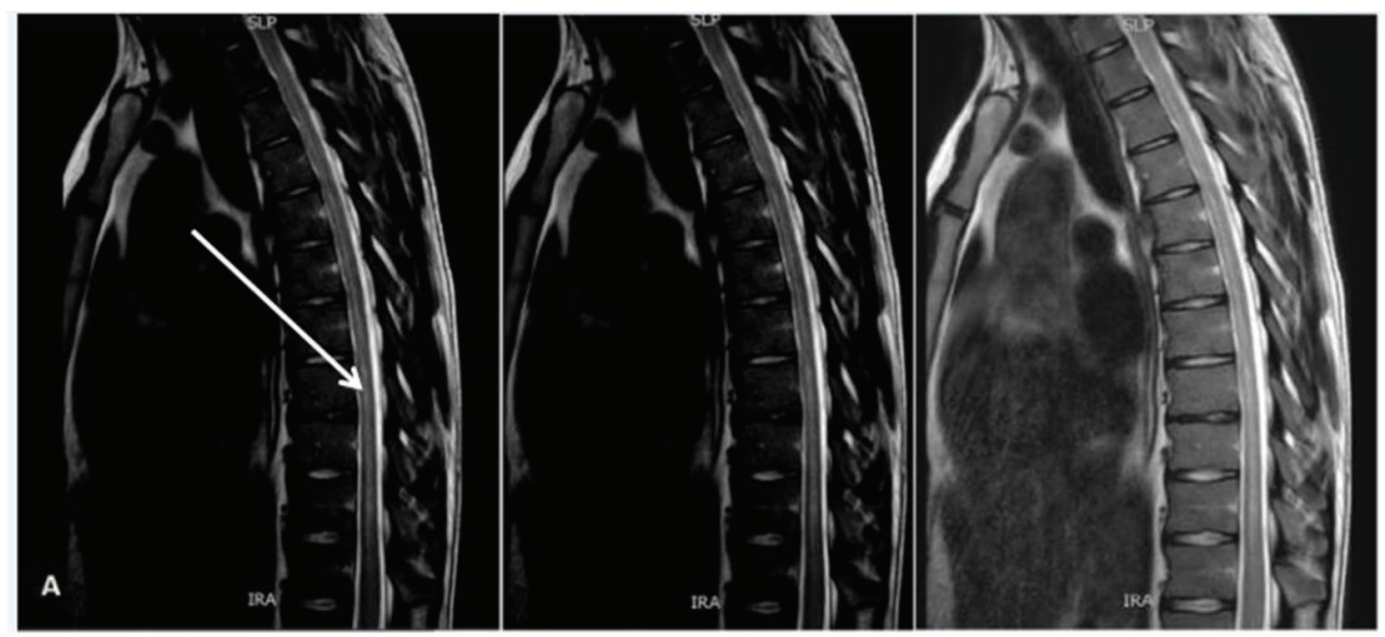

Figure 1. Magnetic resonance imaging of spinal column showing transverse myelitis.

Patient remains in outpatient treatment with partial response to therapy.

\section{Discussion}

Because it is a highly prevalent disease endemic in Brazil and other tropical countries, dengue fever and its complications must be considered a differential diagnosis when patients have acute febrile diseases [4]. The incidence of neurological complications has been increasingly; however, the exact number of cases remains unknown [4].

Dengue is caused by four serotypes, of which serotypes 2 and 3 are most commonly related to neurological complications [5]. The involvement of the spine is rare and is probably caused by direct invasion of the virus causing immune reactions that contribute to the pathophysiology of transverse myelitis [6].

Carod-Artal et al [2] claim that the main manifestations of post-dengue transverse myelitis are lower extremity weakness and urinary retention, i.e. it causes a flaccid paresis phase, which often evolves into a spastic condition as is reported in this case [4].

On investigating voiding dysfunction in 18 patients with transverse myelitis of different etiology not just after dengue, Kalita et al [7] found that of 14 MRI scans, only one patient had changes similar to those found in this case report. Seventeen of these patients had episodes of urinary retention, and most evolved with symptoms of urgency incontinence, increased frequency and voiding effort, with the urodynamic study sup- porting detrusor hyperreflexia. Thus, the patient's symptoms in this case are in agreement with the findings of these authors.

Another manner to analyze the presented lesion is to use the classification of suprapontine lesions in which detrusor overactivity without dyssynergia and suprasacral injury are expected. This condition initially results in a period of spinal shock with areflexia with eventual recovery [8]. This case was compatible to an upper motor neuron lesion.

Erectile dysfunction, first identified in over 40-year-old men (Massachusetts Male Aging Study), is the main symptom of sexual dysfunction [9]. However, in a young patient, as in this case, one should remember the hypothesis of a psychogenic origin as the cause of erectile dysfunction noting that the patient had hormonal levels within the normal range [10]. Nevertheless, it is important to remember that spinal cord injury is a risk factor for this dysfunction [11].

The treatment provided to the patient to reduce urgency and improve sexual function is reported in the literature but no work was found on this specific case or any medication with better response.

In conclusion, transverse myelitis after dengue fever is a rare complication and little is reported in the literature, especially in respect to voiding and sexual dysfunction in young patients with no other risk factors. Thus, it is essential that more research be carried out, so we can help affected patients.

\section{Conflicts of Interest}

None.

Table 1. Hormonal Levels of the Patient With Dengue Fever

\begin{tabular}{lll}
\hline Hormone & Values & Reference range \\
\hline Total testosterone & $23.57 \mathrm{nmol} / \mathrm{L}$ & $10.4-31.2 \mathrm{nmol} / \mathrm{L}$ \\
SHBG & $40.7 \mathrm{nmol} / \mathrm{L}$ & $20-60 \mathrm{nmol} / \mathrm{L}$ \\
Albumina & $4.2 \mathrm{~g} / \mathrm{dL}$ & $3.5-5.0 \mathrm{~g} / \mathrm{dL}$ \\
\hline
\end{tabular}

SHBG: sex hormone-binding globulin. 


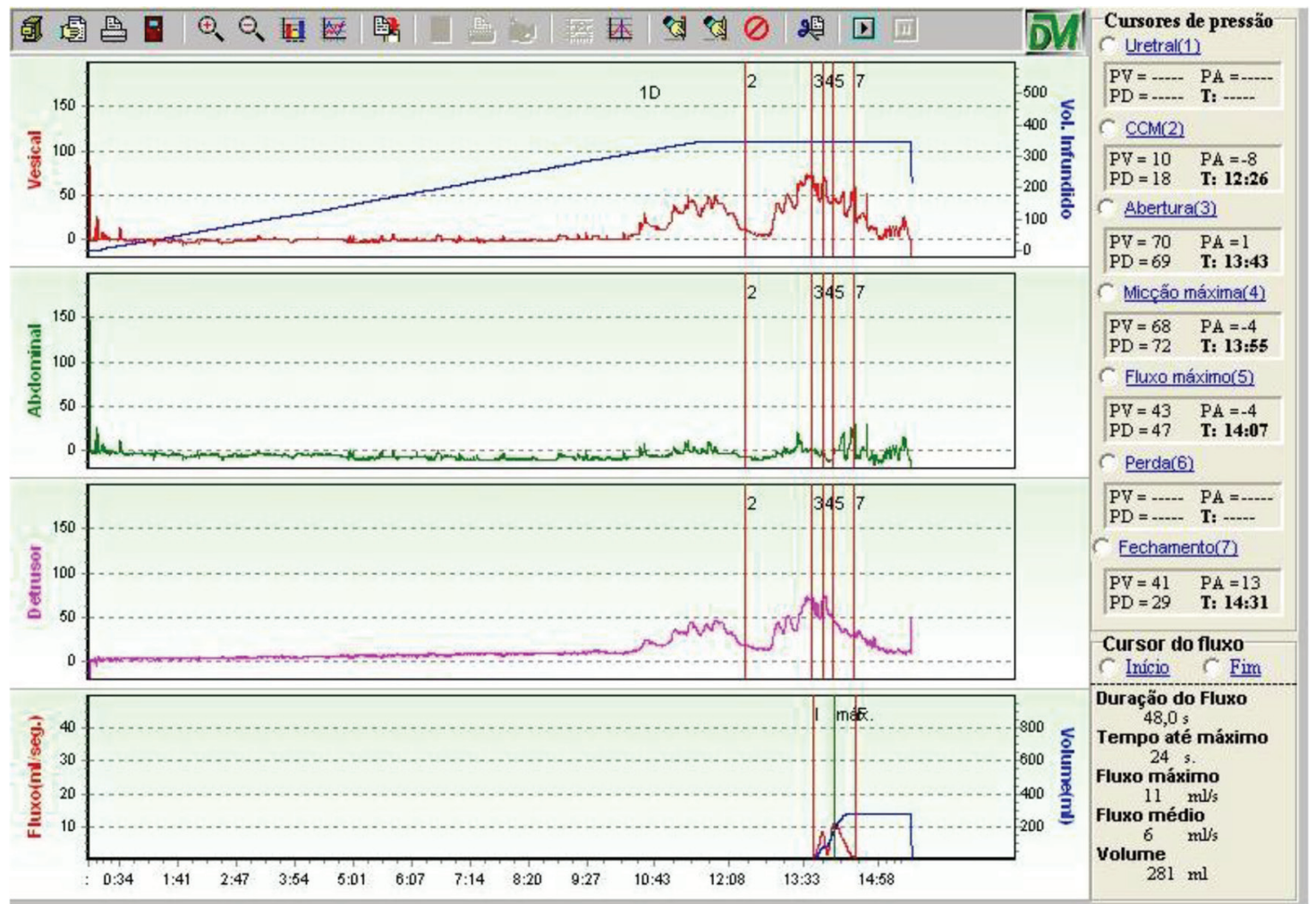

Figure 2. Flow cystometry showing detrusor hyperactivity, increased micturition detrusor pressure and reduced flow.

\section{References}

1. Bhatt S, Gething PW, Brady OJ, Messina JP, Farlow AW, Moyes CL, Drake JM, et al. The global distribution and burden of dengue. Nature. 2013;496(7446):504-507.

2. Carod-Artal FJ, Wichmann O, Farrar J, Gascon J. Neurological complications of dengue virus infection. Lancet Neurol. 2013;12(9):906-919.

3. Brasil. Ministerio da Saude (MS). Dengue: Diagnostico e Manejo Clinico: Adulto e Crianca. Brasilia: MS, Secretaria de Vigilancia em Saude, Departamento de Vigilancia das Doencas Transmissiveis; 2016.

4. Verma R, Sahu R, Holla V. Neurological manifestations of dengue infection: a review. J Neurol Sci. 2014;346(12):26-34.

5. Solomon T, Dung NM, Vaughn DW, Kneen R, Thao LT, Raengsakulrach B, Loan HT, et al. Neurological manifestations of dengue infection. Lancet. 2000;355(9209):10531059.

6. Puccioni-Sohler M, Soares CN, Papaiz-Alvarenga R,
Castro MJ, Faria LC, Peralta JM. Neurologic dengue manifestations associated with intrathecal specific immune response. Neurology. 2009;73(17):1413-1417.

7. Kalita J, Shah S, Kapoor R, Misra UK. Bladder dysfunction in acute transverse myelitis: magnetic resonance imaging and neurophysiological and urodynamic correlations. J Neurol Neurosurg Psychiatry. 2002;73(2):154159.

8. Fowler CJ, Griffiths D, de Groat WC. The neural control of micturition. Nat Rev Neurosci. 2008;9(6):453-466.

9. Feldman HA, Goldstein I, Hatzichristou DG, Krane RJ, McKinlay JB. Impotence and its medical and psychosocial correlates: results of the Massachusetts Male Aging Study. J Urol. 1994;151(1):54-61.

10. Vermeulen A, Oddens BJ. (Eds.) Androgens and the Aging Male. New York: Parthenon Publishing. 1996. p. 3-14.

11. Gratzke C, Angulo J, Chitaley K, Dai YT, Kim NN, Paick JS, Simonsen U, et al. Anatomy, physiology, and pathophysiology of erectile dysfunction. J Sex Med. 2010;7(1 Pt 2):445-475. 